\title{
Renalase and hypertension-demographic and clinical correlates in obstructive sleep apnea
}

\author{
Helena Martynowicz ${ }^{1}$ Karolina Czerwińska ${ }^{2}$ Anna Wojakowska ${ }^{1}$ Lidia Januszewska ${ }^{2}$ Iwona Markiewicz-Górka ${ }^{2}$. \\ Mieszko Więckiewicz ${ }^{3} \cdot$ Grzegorz Mazur $^{1} \cdot$ Krystyna Pawlas $^{2} \cdot$ Rafał Poręba $^{1} \cdot$ Paweł Gać $^{2}$ (I)
}

Received: 9 March 2020 /Revised: 18 July 2020 / Accepted: 28 July 2020 / Published online: 6 August 2020

(C) The Author(s) 2020

\begin{abstract}
Background Renalase plays an important role in blood pressure regulation. Obstructive sleep apnea (OSA) is a common respiratory disorder associated with hypertension and cardiovascular complications. The aim of the study was to assess the relationship between sleep apnea and renalase concentration.

Material and methods Adult patients $(n=113)$ were evaluated for OSA in a sleep laboratory using polysomnography. The respiratory events were scored according to the standards developed by the American Academy of Sleep Medicine. The blood renalase concentration was determined by the ELISA (enzyme-linked immunosorbent assay) test.

Results OSA (AHI $\geq 5)$ was diagnosed in $71 \%(n=80)$ of the studied population. Renalase concentration was statistically significantly lower in the group with moderate-to-severe OSA $(\mathrm{AHI} \geq 15)$ compared with the group without OSA $(\mathrm{AHI}<5)$ $(139.56 \pm 175.72 \mathrm{ng} / \mathrm{ml}$ vs. $230.97 \pm 240.50 \mathrm{ng} / \mathrm{ml}, p=0.042)$. We have found statistically significant negative correlation between renalase and AHI in hypertensives, but not in normotensives. The statistically significant negative correlation was observed between AHI and renalase in the whole studied group, in males, and in the group of age $<60$ years old. There was not such a correlation in females and in the group $>60$ years old. Based on the regression model, it was shown that lower renalase concentration, hypertension, higher BMI, and male gender are independently associated with higher AHI.

Conclusions There is a relationship between the blood renalase concentration and the severity of OSA, which may influence hypertension development in OSA.
\end{abstract}

Keywords Renalase $\cdot$ Obstructive sleep apnea $\cdot$ Hypertension

\section{Introduction}

Obstructive sleep apnea (OSA) is a common disorder characterized by recurrent episodes of either complete upper airway collapse (apneas) or partial collapse (hypopneas) during sleep

Paweł Gać

pawelgac@interia.pl

1 Department of Internal Medicine, Occupational Diseases, Hypertension and Clinical Oncology, Wroclaw Medical University, 213 Borowska St., 50-556 Wroclaw, Poland

2 Department of Hygiene, Wroclaw Medical University, 7 Mikulicza-Radeckiego St., 50-345 Wroclaw, Poland

3 Department of Experimental Dentistry, Wroclaw Medical University, 26 Krakowska St., 50-425 Wroclaw, Poland leading to arterial oxygen desaturation, frequently terminated by arousal [1]. OSA is independently associated with cardiovascular morbidity and mortality [2-5]. The meta-analysis determined that severe OSA (apnea/hypopnea index $\geq 30$ ) was associated with increased cardiovascular mortality with a hazard ratio of 2.73 [6]. The parameter that defines the severity of OSA is the apnea/hypopnea index (AHI), which indicates the number of episodes per hour. OSA is diagnosed if an $\mathrm{AHI} \geq 5$ events per hour. AHI between 5 and 15 indicates mild OSA, between 15 and 30 - moderate OSA, and more than 30-severe OSA [7]. It was demonstrated that about $50 \%$ of patients with OSA have underlying arterial hypertension [7, 8]. Recent meta-analysis, involving 20 original studies in 19 articles, demonstrates that OSA increases the risk of hypertension in a dose-response manner [9]. The pathogenesis of hypertension in OSA are complex and not fully understood. The main risk factors for OSA are older age, male gender, and obesity [10]. It has been suggested that intermittent 
Fig. 1 The qualification scheme for recruitment for the research project
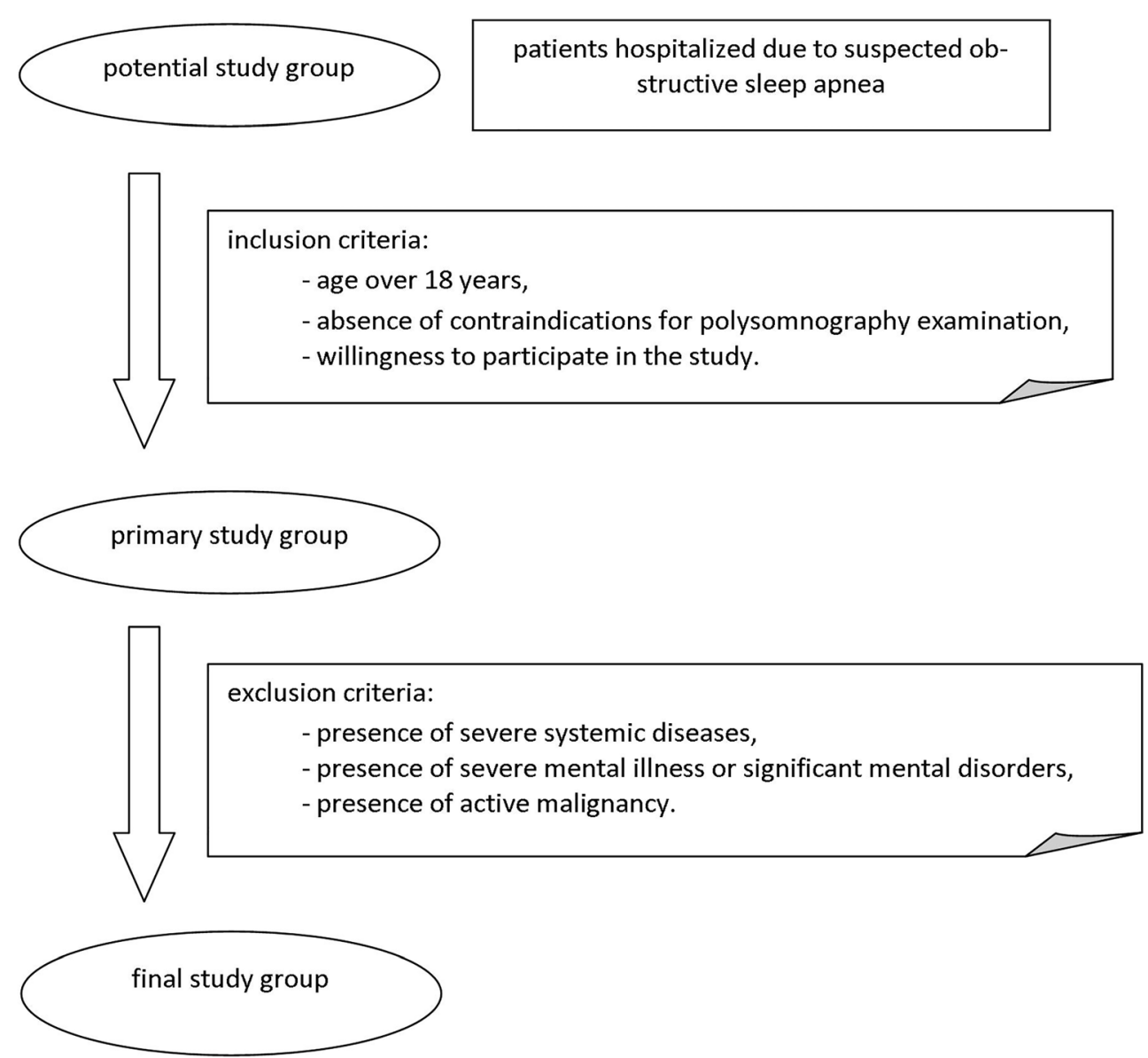

hypoxemia, sleep fragmentation, nocturnal fluid shift, activation of renin-angiotensin-aldosterone (RAA) system, and endothelial dysfunction may play a role in increase of blood pressure. During OSA episodes, there may be an upregulation of the sympathetic nervous system which, through chemoreceptor reflexes, can cause hypertension [11, 12]. Metaanalysis on OSA treatment with CPAP treatment trials found a low reduction of blood pressure $(2.6 \mathrm{mmHg}$ for systolic and $2.0 \mathrm{mmHg}$ for diastolic blood pressure) [12]. Thus, CPAP does not seem to be the effective in blood pressure reduction and novel and more effective methods of treatment are needed.

Renalase, one of the recently discovered flavoproteins, is possibly an important determinant of cardiovascular health. Renalase has been shown to be responsible for the elimination of circulating catecholamines in the plasma [13-15]. Catecholamines are involved in sympathetic activation; thus, renalase may play a crucial role in pathogenesis of arterial hypertension [16]. Desir et al. showed that the decrease of renalase gene expression about $40 \%$ if followed by the blood pressure increased by $13 \mathrm{mmHg}$ [16]. At least two single nucleotide polymorphisms of the renalase gene have been documented as risk factors for the development of hypertension [17]. The increased renalase has been reported in patients with arterial hypertension [16] and positively related to blood pressure in clinical studies [18, 19]. Recently, the relationship between blood renalase concentration and the intensity of sleep bruxism has been shown [20].

The aim of the study was to assess the relationship between sleep apnea and blood renalase concentration as a possible mechanism of the development of arterial hypertension in patients with OSA.

\section{Material and methods}

The research was carried out on a group of 113 adult patients hospitalized in an internal medicine clinic to verify the suspicion of OSA. The criteria for qualifying patients for the study were as follows: consent to participate in the study, age $\geq$ 18 years, and no contraindications for polysomnography (PSG). The criteria for disqualification from the study were as follows: coexistence of severe systemic diseases, coexistence of severe mental illness/mental disorders, and coexistence of active proliferative disease. The qualification scheme for recruitment for the research project is shown in Fig. 1.

PSG was performed according to a diagnostic standard as a nocturnal, single-night recording, using the Nox-A1 machine 
Table 1 Parameters of polysomnographic examination in the examined group $(n=113)$

\begin{tabular}{llll}
\hline Parameter & Mean $\pm \mathrm{SD}$ & Minimum & Maximum \\
\hline $\mathrm{SE}$ & $81.80 \pm 10.08$ & 52.40 & 98.30 \\
$\mathrm{SL}$ & $21.38 \pm 21.20$ & 0.00 & 112.60 \\
$\mathrm{~W} A \mathrm{SO}$ & $56.63 \pm 43.73$ & 1.00 & 186.00 \\
$\mathrm{~N} 1(\%)$ & $5.01 \pm 4.23$ & 0.30 & 21.20 \\
$\mathrm{~N} 2(\%)$ & $46.01 \pm 11.73$ & 4.30 & 78.70 \\
$\mathrm{~N} 3(\%)$ & $26.70 \pm 11.21$ & 2.60 & 54.90 \\
REM $(\%)$ & $21.89 \pm 7.62$ & 4.10 & 38.40 \\
$\mathrm{AHI}$ & $17.98 \pm 18.82$ & 0.00 & 87.40 \\
OAI & $5.67 \pm 11.65$ & 0.00 & 71.20 \\
MAI & $0.19 \pm 1.40$ & 0.00 & 14.80 \\
$\mathrm{CAI}$ & $0.76 \pm 2.55$ & 0.00 & 17.60 \\
$\mathrm{Ch}-\mathrm{S} \mathrm{R}$ & $0.85 \pm 2.76$ & 0.00 & 16.80 \\
Min SatO & $83.49 \pm 8.03$ & 54.00 & 95.00 \\
Mean SatO & $93.21 \pm 2.46$ & 83.30 & 97.30 \\
ODI & $17.22 \pm 18.25$ & 0.00 & 88.40 \\
\hline
\end{tabular}

$S E$ sleep efficiency, $S L$ sleep latency, WASO wake after sleep onset, $R E M$ rapid eye movement, $A H I$ apnea-hypopnea index, $O A I$ obstructive apnea index, MAI mixed apnea index, $C A I$ central apnea index, $C h-S R$ CheyneStokes respiration, $\mathrm{MinSatO}_{2}$ minimal oxygen saturation, mean $\mathrm{SatO}_{2}$ mean oxygen saturation, $O D I$ oxygen desaturation index

(Nox Medical, Iceland). The PSG recordings included electroencephalography, electromyography, electrooculography, pulse oximetry, electrocardiography, and a microphone. The airflow was measured using a nasal pressure transducer, and the respiratory effort of thoracoabdominal movement was measured using respiratory inductance plethysmography. Polysomnograms were assessed in 30-s epochs according to the typical criteria for assessing the quality of sleep developed by the well-known American Academy of Sleep Medicine (AASM) [21]. The following polysomnographic parameters were assessed: total sleep time ( $\mathrm{min})$, sleep latency $(\mathrm{min})$, sleep efficiency (\%), and the percentages of duration of subsequent sleep phases: N1, N2, N3, and REM. The AHI was defined as the average number of episodes of apnea and hypopnea per hour of total sleep time (TST). Apnea was attained with the reduction of air flow to less than $10 \%$ of the baseline for at least $10 \mathrm{~s}$. A hypopnea episode was defined as a decrease in the nasal pressure signal by at least 30\% from baseline for at least $10 \mathrm{~s}$, with a reduction in $\mathrm{O}_{2}$ saturation of at least 3\% from the pre-event baseline or an arousal.

Blood was collected in the morning after polysomnography, usually by puncturing the veins of the ulna. Until renalase determinations were performed simultaneously in all samples, the blood was stored at a constant temperature. Serum renalase determinations were performed using the E3109Hu kit ELISA (enzyme-linked immunosorbent assay) (Bioassay Technology Laboratory,
Shanghai, China). The determinations were made strictly according to the test manufacturer's instructions. The renalase concentration was expressed in the unit nanogram per milliliter. The reference range of the assay used was $1-400 \mathrm{ng} / \mathrm{ml}$. According to the manufacturer, the sensitivity of the ELISA test used was $0.52 \mathrm{ng} / \mathrm{ml}$. The coefficient of intra- and interassay variation was $<8 \%$ and $<10 \%$.

Statistical analyses were conducted using Dell Statistica 13 software (Dell Inc., USA). The quantitative variables were expressed as means and standard deviations. The qualitative variables were expressed as percentages. The distribution of variables was tested with the W-Shapiro-Wilk test. In the case of the quantitative variables of normal distribution, a further statistical analysis used $T$ test. For non-normally distributed quantitative variables, the Mann-Whitney $U$ test was used. For qualitative variables, in further statistical analysis, the chisquare test of maximum likelihood was used. To determine the relation between the examined variables, the correlation and regression analysis has been conducted. In the case of normal distribution, the Pearson correlation $r$ factors have been determined whereas in the case of non-normal distribution, the Spearman $r$ factors have been applied. The possible factors related to AHI value were found on the basis of the univariable linear regressions between AHI value and basic anthropometrical data (age, BMI, gender), cardiovascular diseases (hypertension, coronary artery diseases, type 2 diabetes), and also renalase concentration. Then, using multivariable stepwise regression analysis, taking into account statistically significant factors demonstrated in univariate analyses, the final model for the AHI value was obtained. The parameters of the models obtained in the regression analysis have been estimated by the application of the least square's method. Results with $p<0.05$ were considered statistically significant.

The studies were carried out as part of a research project entitled "The importance of relationship between selenium and zinc deficiency and blood renalase concentration in the pathogenesis of subclinical cardiovascular complications of hypertension," according to the records in the Simple system with the number SUB.A100.19.009, which obtained the consent of the local Bioethics Committee.

\section{Results}

The mean age of all participants was $49.70 \pm 14.60$ years. Women constituted $53 \%(n=60)$ of all participants. The mean BMI was found to be $28.71 \pm 5.3 \mathrm{~kg} / \mathrm{m}^{2}$. Diabetes and ischemic heart disease were diagnosed in $9.7 \%(n=11)$ and $7.07 \%$ $(n=8)$ of the study population, respectively. Thirty-eight percent $(n=43)$ were diagnosed as hypertensives.

OSA (AHI $\geq 5)$ was diagnosed in $71.42 \%(n=80)$ of the studied population. The mild (AHI 5-15), moderate (AHI 1530 ), and severe (AHI $\geq 30$ ) OSA were diagnosed in $28.57 \%$ 
Table 2 Parameters of polysomnographic examination in studied group divided due to first quartile of renalase concentration (with renalase concentration $<36.43 \mathrm{ng} / \mathrm{ml}$ and renalase $\geq 36.43 \mathrm{ng} / \mathrm{ml}$ )

\begin{tabular}{llll}
\hline & Renalase $<36.43 \mathrm{ng} / \mathrm{ml}$ & Renalase $\geq 36.43 \mathrm{ng} / \mathrm{ml}$ & $p$ \\
\hline $\mathrm{SE}$ & $83.98 \pm 9.42$ & $81.20 \pm 10.30$ & 0.239 \\
$\mathrm{SL}(\mathrm{min})$ & $15.44 \pm 12.72$ & $23.27 \pm 15.79$ & 0.114 \\
$\mathrm{WASO}$ & $56.44 \pm 51.28$ & $53.11 \pm 41.75$ & 0.746 \\
$\mathrm{~N} 1(\%)$ & $4.64 \pm 3.48$ & $5.12 \pm 4.47$ & 0.632 \\
$\mathrm{~N} 2(\%)$ & $50.54 \pm 13.68$ & $44.70 \pm 10.90$ & $0.032^{*}$ \\
$\mathrm{~N} 3(\%)$ & $23.92 \pm 11.02$ & $27.46 \pm 11.26$ & 0.177 \\
$\mathrm{REM}(\%)$ & $20.90 \pm 9.26$ & $22.21 \pm 7.14$ & 0.464 \\
$\mathrm{AHI}$ & $24.14 \pm 23.22$ & $15.35 \pm 15.76$ & $0.028^{*}$ \\
OAI & $7.72 \pm 12.29$ & $4.23 \pm 8.90$ & 0.111 \\
MAI & $0.64 \pm 2.83$ & $0.04 \pm 0.16$ & 0.053 \\
$\mathrm{CAI}$ & $1.90 \pm 4.58$ & $0.41 \pm 1.25$ & $0.008^{*}$ \\
$\mathrm{Ch}-\mathrm{S} \mathrm{R}(\%)$ & $2.02 \pm 4.85$ & $0.48 \pm 1.47$ & $0.012^{*}$ \\
Min SatO & $80.65 \pm 8.90$ & $84.73 \pm 6.85$ & $0.015^{*}$ \\
Mean $\mathrm{SatO}_{2}$ & $92.21 \pm 2.34$ & $93.64 \pm 2.16$ & $0.004 *$ \\
ODI & $21.72 \pm 21.80$ & $15.14 \pm 15.74$ & 0.093
\end{tabular}

Mean \pm SD

$S E$ sleep efficiency, $S L$ sleep latency, WASO wake after sleep onset, $R E M$ rapid eye movement, $A H I$ apnea-hypopnea index, $O A I$ obstructive apnea index, $M A I$ mixed apnea index, $C A I$ central apnea index, $C h-S R$ CheyneStokes respiration, $\mathrm{MinSatO}_{2}$ minimal oxygen saturation, mean $\mathrm{SatO}_{2}$ mean oxygen saturation, $O D I$ oxygen desaturation index

*Statistically significant $(n=32), 18.75 \%(n=21)$, and $24.10 \%(n=27)$ of the study population, respectively. The mean apnea/hypopnea index (AHI) was $17.98 \pm 18.82$. The polysomnographic parameters in the studied group are presented in Table 1.

The mean concentration of renalase was $185.61 \pm$ $213.38 \mathrm{ng} / \mathrm{ml}$ in the entire study group. There was no statistically significant difference in renalase concentration in the group with OSA $(\mathrm{AHI} \geq 5)$ and controls without OSA (AHI <5) $(169.15 \pm 200.98 \mathrm{ng} / \mathrm{ml}$ vs. $230.97 \pm 240.50 \mathrm{ng} / \mathrm{ml}, p=$ $0.168)$. However, renalase concentration was statistically significantly lower in the group with moderate-to-severe OSA (AHI $\geq 15)$ compared with the group without OSA (AHI < 5) $(139.56 \pm 175.72 \mathrm{ng} / \mathrm{ml}$ vs. $230.97 \pm 240.50 \mathrm{ng} / \mathrm{ml}, p=$ 0.042). Furthermore, renalase concentration was statistically significantly lower in the group with moderate-to-severe OSA $(\mathrm{AHI} \geq 15)$ compared with the group with mild-to-no OSA $(\mathrm{AHI}<15)(139.56 \pm 175.72 \mathrm{ng} / \mathrm{ml}$ vs. $221.76 \pm 233.23 \mathrm{ng} / \mathrm{ml}$, $p=0.044)$.

The statistically significant negative correlation was observed between AHI and renalase in the entire study group ( $r=-0.19, p=0.039$; Fig. 2$)$, in males $(r=-0.29, p=0.046)$, and in the group of age $<60(r=-0.20 ; p=0.042)$. There was not such a correlation in females and in the group $>60$ years old. The statistically significant negative correlation was also

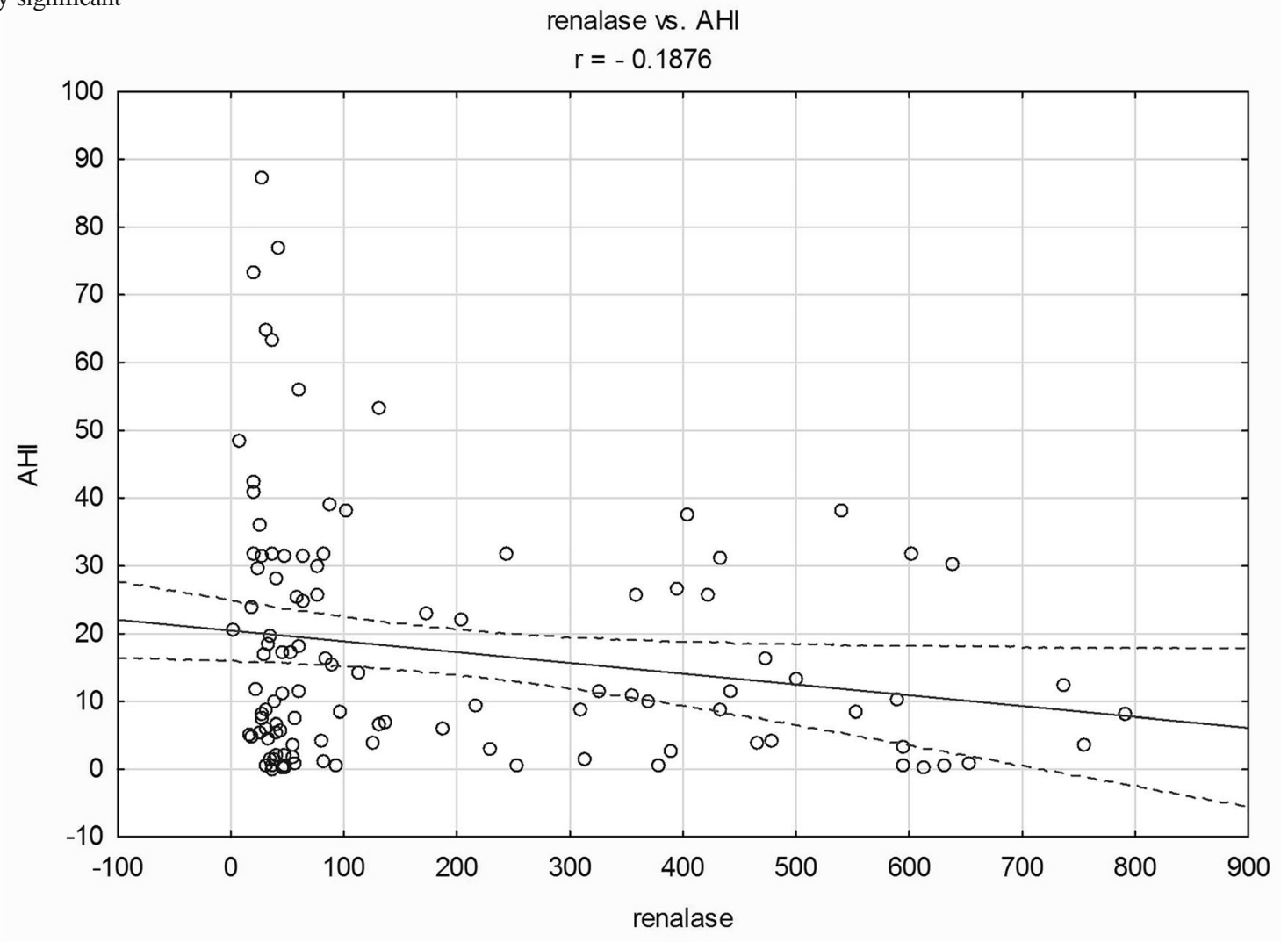

Fig. 2 The correlation between renalase $(\mathrm{ng} / \mathrm{ml})$ and $\mathrm{AHI}$ in whole studied group 
Table 3 Univariate and multivariable stepwise regression models determining factors related to AHI values in the study group

\begin{tabular}{|c|c|c|c|c|c|}
\hline & \multicolumn{5}{|c|}{ Model for: AHI } \\
\hline & \multicolumn{2}{|c|}{ Univariate regression } & \multicolumn{3}{|c|}{ Multivariable regression } \\
\hline & $\mathrm{Rc}$ & $p$ & $\mathrm{Rc}$ & SEM of Rc & $p$ \\
\hline Intercept & - & - & -2.966 & 2.924 & $0.042 *$ \\
\hline Age (years) & 0.535 & $0.001 *$ & 0.181 & 0.157 & 0.253 \\
\hline BMI $\left(\mathrm{kg} / \mathrm{m}^{2}\right)$ & 1.119 & $0.010^{*}$ & 0.644 & 0.393 & $0.011 *$ \\
\hline Male sex & 15.570 & $0.001 *$ & 11.268 & 4.039 & $0.007 *$ \\
\hline Coronary artery diseases & 22.641 & $0.001 *$ & 9.937 & 6.913 & 0.155 \\
\hline Type 2 diabetes & 0.518 & 0.934 & - & - & - \\
\hline Hypertension & 14.454 & $0.002 *$ & 5.605 & 4.430 & $0.021 *$ \\
\hline Renalase (ng/ml) & -0.016 & $0.039 *$ & -0.007 & 0.009 & $0.047^{*}$ \\
\hline
\end{tabular}

$A H I$ apnea/hypopnea index, $B M I$ body mass index

*Statistically significant observed between $\mathrm{AHI}$ and renalase in hypertensives and in the group with OSA $(\mathrm{AHI} \geq 5)(r=-0.22, r=-0.17$, respectively). There was not such a correlation in normotensives and in healthy controls $(\mathrm{AHI}<5)$. We have also observed statistically significant negative correlation between renalase and oxygen desaturation index (ODI) $(r=-0.18, p=0.041)$ and between renalase and mean desaturation $(r=-0.18, p=$ 0.039 ) in the entire study group.

Then, we divided the study group according to the following criteria: first quartile, median, and third quartile renalase concentration. Statistically significant differences were obtained only in comparison of subgroups separated by 1 quartile of renalase concentration. We have observed increased AHI, mean oxygen saturation $\left(\mathrm{SatO}_{2}\right)$, minimal oxygen saturation, stage N1 sleep duration, central apnea index, and Cheyne-Stokes breathing duration in the group with renalase concentration $<$ first quartile compared with the group with renalase concentration $\geq$ first quartile (renalase $<36.43 \mathrm{ng} / \mathrm{ml}$ vs. renalase $\geq 36.43 \mathrm{ng} / \mathrm{ml}$ ) (Table 2).

The correlation analysis showed the existence of statistically significant relationships between $\mathrm{AHI}$ on the one hand and male sex, BMI, age, hypertension, and ischemic heart disease on the other $(r=0.41, r=0.30, r=0.41, r=0.37, r=0.31$; respectively).

With the use of a multivariable stepwise regression analysis of statistically significant variables from univariate regressions (male sex, BMI, age, hypertension, coronary artery diseases, and renalase concentration), a final model was obtained with the $\mathrm{AHI}$ as the dependent variable:

$$
\begin{aligned}
\mathrm{AHI}= & -2.966-0.007 \text { renalase }+5.605 \text { hypertension } \\
& +0.644 \mathrm{BMI}+11.268 \text { male sex }
\end{aligned}
$$

Based on the regression model that was obtained, it was shown that lower renalase concentration, hypertension, higher BMI, and male sex are independently associated with higher AHI values (Table 3 ).

\section{Discussion}

The most important result of this study is the finding of an inversely proportional linear relationship between renalase concentration and AHI values in the entire study group. The result indicates association between OSA and renalase, which is an enzyme involved in hypertension development. We have also observed linear negative correlations between renalase concentration and mean oxygen desaturation, but not mean oxygen saturation $\left(\mathrm{SatO}_{2}\right)$. This result indicates role of variability of blood oxygen saturation more than stable hypoxemia in OSA pathomechanism.

Then, we have divided the study group into subgroups: group with $\mathrm{AHI} \geq 15$ and group with $\mathrm{AHI}<15$, since moderate-to-severe OSA (AHI $\geq 15$ ) is associated with increased cardiovascular risk [22]. We have found decreased renalase concentration in the group with moderate and severe OSA (AHI $\geq 15$ ) compared with the group with $\mathrm{AHI}<15$. In patients with moderate-to-severe OSA compared with mild OSA, the risk of hypertension is also significantly higher [23]. Recently Hou confirmed association between moderate and severe OSA and hypertension, but not mild OSA [23]. In the study, we have observed negative linear correlation between renalase concentration and AHI in hypertensives, but not in normotensives. Since renalase is known as essential hypotensive factor, decreased levels of the enzyme might lead to hypertension development. Thus, the result of the study agrees with previous studies and might indicate the role of renalase in hypertension pathogenesis due to sleep apnea. 
It is noteworthy that some studies raised the relationship between OSA and hypertension in a gender. Recently, metaanalysis showed that men suffer from higher incidence of essential hypertension than women, as well the association in Caucasians is greater than that in Asians [9]. It was also demonstrated that an RDI (respiratory disturbance index) $\geq 14$ was associated with a increased risk for hypertension for men. This association was not statistically significant among women [24]. Interestingly, we have also observed correlation between renalase and AHI in males. However, there was no correlation between renalase and AHI in females. The results suggest an association between OSA and hypertension occurring in men but not in women in both studies.

We have observed correlation between renalase and $\mathrm{AHI}$ in group $<60$ years old, but not in the group $>60$ years old. The recent review of the overall body of evidence confirms that advancing age, male sex, and higher body mass index increase OSA prevalence [25]. The data concerning influence of age on hypertension development in OSA are limited. The prevalence of hypertension increases with age; however, this result may indicate different mechanisms of hypertension in older age. Due to present study, renalase is correlated with OSA in younger participants and consequently may be involved in hypertension pathogenesis in age ranges $<60$ years old.

We have found increased stage N2 sleep duration in the group with low renalase concentration (in the first quartile of renalase concentration $<36.43 \mathrm{ng} / \mathrm{ml}$ ) compared with the group with higher renalase concentration (>36.43). This result indicates worse sleep quality in patients with low renalase concentration. Increased duration of light sleep stages accompanied with decreased deep stages of sleep was observed in sleep apnea [26]. We have observed increased AHI in the group with low renalase concentration, which agrees with these studies. We have also found increased central apnea index and Cheyne-Stokes respiration duration in the group with low renalase concentration. Cheyne-Stokes respiration occurs with CSA (central sleep apnea) and is characterized by cyclical crescendo-decrescendo respiratory effort that occurs without upper airway obstruction [27, 28]. CheyneStokes breathing in CSA is usually more common during the NREM sleep phase, especially during periods N1 and $\mathrm{N} 2$ [29].

There was a negative correlation between renalase and AHI in the group with OSA (AHI > 5), but not in healthy controls $(\mathrm{AHI}<5)$, which may suggest the involvement of renalase in OSA pathomechanism. We have also confirmed relationship between $\mathrm{AHI}$ and male gender, BMI, age, hypertension, and ischemic heart disease. Based on the segment multifactorial regression analysis performed in the entire study group, we have found that lower blood renalase concentration, hypertension, higher BMI, and male gender are independently associated with higher AHI. The association between OSA and hypertension [30], BMI [31], age [32], and male gender [33] was showed in numerous previous studies. To our knowledge, it is the first study which demonstrated relationship between OSA and renalase. The results of the study might indicate the role of renalase in OSA and comorbid hypertension pathogenesis.

The main disadvantage of this study is the absence of both office and ambulatory blood pressure monitoring values for participants. We have neither asses the level of catechalamine's. The gender distribution in the studied group differs from the typical one-we have over-representation of women.

In summary, we showed a relationship between blood renalase concentration and obstructive sleep apnea. It is worth noting that recently our research team demonstrated the role of renalase in sleep bruxism [20]; thus, renalase holds promise as a potential important factor of hypertension pathomechanism during sleep in both sleep bruxism and obstructive sleep apnea.

Funding information The study was funded by local grant from the Wroclaw Medical University (no. SUB.A100.19.009).

\section{Compliance with ethical standards}

Conflict of interest The authors declare that they have no conflict of interest.

Ethical approval All procedures performed in studies involving human participants were in accordance with the ethical standards of the Bioethics Committee of Bioethics Committee of Wroclaw Medical University.

Informed consent Informed consent was obtained from all individual participants included in the study.

Open Access This article is licensed under a Creative Commons Attribution 4.0 International License, which permits use, sharing, adaptation, distribution and reproduction in any medium or format, as long as you give appropriate credit to the original author(s) and the source, provide a link to the Creative Commons licence, and indicate if changes were made. The images or other third party material in this article are included in the article's Creative Commons licence, unless indicated otherwise in a credit line to the material. If material is not included in the article's Creative Commons licence and your intended use is not permitted by statutory regulation or exceeds the permitted use, you will need to obtain permission directly from the copyright holder. To view a copy of this licence, visit http://creativecommons.org/licenses/by/4.0/.

\section{References}

1. Jordan AS, McSharry DG, Malhotra A (2014) Adult obstructive sleep apnoea. Lancet. 383:736-747

2. Gami AS, Howard DE, Olson EJ, Somers VK (2005) Day-night pattern of sudden death in obstructive sleep apnea. N Engl J Med 352:1206-1214

3. Yaggi HK, Concato J, Kernan WN, Lichtman JH, Brass LM, Mohsenin V (2005) Obstructive sleep apnea as a risk factor for stroke and death. N Engl J Med 353:2034-2041 
4. Phillips B (2005) Sleep-disordered breathing and cardiovascular disease. Sleep Med Rev 9:131-140

5. Marin JM, Carrizo SJ, Vicente E, Agusti AG (2005) Long-term cardiovascular outcomes in men with obstructive sleep apnoea hypopnoea with or without treatment with continuous positive airway pressure: an observational study. Lancet 365:1046-1053

6. Benjamin EJ, Muntner P, Alonso A, Bittencourt MS, Callaway CW, Carson AP, Chamberlain AM, Chang AR, Cheng S, Das SR, Delling FN, Djousse L, Elkind MSV, Ferguson JF, Fornage M, Jordan LC, Khan SS, Kissela BM, Knutson KL, Kwan TW, Lackland DT, Lewis TT, Lichtman JH, Longenecker CT, Loop MS, Lutsey PL, Martin SS, Matsushita K, Moran AE, Mussolino ME, O'Flaherty M, Pandey A, Perak AM, Rosamond WD, Roth GA, Sampson UKA, Satou GM, Schroeder EB, Shah SH, Spartano NL, Stokes A, Tirschwell DL, Tsao CW, Turakhia MP, VanWagner LB, Wilkins JT, Wong SS, Virani SS, On behalf of the American Heart Association Council on Epidemiology and Prevention Statistics Committee and Stroke Statistics Subcommittee (2019) Heart Disease and Stroke Statistics-2019 update: a report from the American Heart Association. Circulation. 139:e56-e 528

7. Ahmad M, Makati D, Akbar S (2017) Review of and updates on hypertension in obstructive sleep apnea. Int J Hypertens 2017:1-13

8. Peppard PE, Young T, Palta M, Skatrud J (2000) Prospective study of the association between sleep-disordered breathing and hypertension. N Engl J Med 342(19):1378-1384

9. Hou H, Zhao Y, Yu W, Dong H, Xue X, Ding J, Xing W, Wang W (2018) Association of obstructive sleep apnea with hypertension: a systematic review and meta-analysis. J Glob Health 8(1):010405

10. Young T, Peppard PE, Gottlieb DJ (2002) Epidemiology of obstructive sleep apnea: a population health perspective. Am J Resp Critical Care Med 165(9):1217-1239

11. Fava C, Dorigoni S, Dalle Vedove F, Danese E, Montagnana M, Guidi GC, Narkiewicz K, Minuz P (2014) Effect of CPAP on blood pressure in patients with OSA/hypopnea a systematic review and meta-analysis. Chest. 145:762-771

12. Dopp JM, Reichmuth KJ, Morgan BJ (2007) Obstructive sleep apnea and hypertension: mechanisms, evaluation, and management. Curr Hypertens Rep 9:529-534

13. Desir GV (2009) Regulation of blood pressure and cardiovascular function by renalase. Kidney Int 76(4):366-370

14. Desir G (2012) Novel insights into the physiology of renalase and its role in hypertension and heart disease. Pediatr Nephrol 27(5): 719-725

15. Li G, Xu J, Wang P, Velazquez H, Li Y, Wu Y, Desir GV (2008) Catecholamines regulate the activity, secretion, and synthesis of renalase. Circulation. 117(10):1277-1282

16. Maciorkowska D, Zbroch E, Malyszko J (2015) Circulating renalase, catecholamines, and vascular adhesion protein 1 in hypertensive patients. J Am Soc Hypertens 9:855-864

17. Lv YB, Wang Y, Ma WG, Yan DY, Zheng WL, Chu C, Guo TS, Yuan ZY, Mu JJ (2016) Association of renalase SNPs rs2296545 and rs 2576178 with the risk of hypertension: a meta-analysis. PLoS One 11(7):e0158880

18. Desir GV (2007) Renalase is a novel renal hormone that regulates cardiovascular function. J Am Soc Hypertens 1(2):99-103

19. Wang F, Li J, Xing T, Xie Y, Wang N (2015) Serum renalase is related to catecholamine levels and renal function. Clin Exp Nephrol 19:92-98
20. Martynowicz H, Wieckiewicz M, Poreba R, Wojakowska A, Smardz J, Januszewska L, Markiewicz-Gorka I, Mazur G, Pawlas K, Gac P (2019) The relationship between sleep bruxism intensity and renalase concentration - an enzyme involved in hypertension development. J Clin Med 9(1):16

21. Berry RB, Budhiraja R, Gottlieb DJ, Gozal D, Iber C, Kapur VK, Marcus CL, Mehra R, Parthasarathy S, Quan SF, Redline S, Strohl KP, Davidson Ward SL, Tangredi MM, American Academy of Sleep Medicine (2012) Rules for scoring respiratory events in sleep: update of the 2007 AASM Manual for the Scoring of Sleep and Associated Events. Deliberations of the Sleep Apnea Definitions Task Force of the American Academy of Sleep Medicine. J Clin Sleep Med 8:597-619

22. Aartz M, Young T, Finn L, Skatrud JB, Bradley D (2005) Association of sleep-disordered breathing and the occurence of stroke. Am J Respir Crit Care Med 172:1447-1451

23. Hou H, Zhao Y, Yu W, Dong H, Xue X, Ding J, Xing W, Wang W (2018) Association of obstructive sleep apnea with hypertension: a systematic review and meta-analysis. J Glob Health 8(1):010405

24. Cano-Pumarega I, Barbé F, Esteban A, Martínez-Alonso M, Egea C, Durán-Cantolla J (2017) Sleep apnea and hypertension: are there sex differences? Vitoria Sleep Cohort Chest 152:742-750

25. Senaratna CV, Perret JL, Lodge CJ, Lowe AJ, Campbell BE, Matheson MC, Hamilton GS, Dharmage SC (2017) Prevalence of obstructive sleep apnea in the general population: a systematic review. Sleep Med Rev 34:70-81

26. Redline S, Kirchner H, Quan SF, Gottlieb DJ, Kapur V, Newman A (2004) The effects of age, sex, ethnicity, and sleep-disordered breathing on sleep architecture. Arch Intern Med 164(4):406-418

27. Javaheri S (2017) Heart failure. In: Kryger MH, Roth T, Dement WC (eds) Principles and practice of sleep medicine, 6th edn. Elsevier, Philadelphia, pp 1271-1285

28. Olson LJ, Somers VK (2007) Treating central sleep apnea in heart failure: outcomes revisited. Circulation 115(25):3140-3142

29. Mehra R (2019) Sleep apnea and the heart. Cleve Clin J Med 86(9 Suppl 1):10-18

30. Lavie P, Herer P, Hoffstein V (2000) Obstructive sleep apnoea syndrome as a risk factor for hypertension: population study. BMJ. 320:479-482

31. Young T, Shahar E, Nieto FJ, Redline S, Newman AB, Gottlieb DJ, Walsleben JA, Finn L, Enright P, Samet JM, Sleep Heart Health Study Research Group (2002) Predictors of sleep-disordered breathing in community-dwelling adults. Arch Intern Med 162(8): 893-900

32. Mehra R, Stone KL, Blackwell T, Ancoli Israel S, Dam TTL, Stefanick ML, Redline S, for the Osteoporotic Fractures in Men Study (2007) Prevalence and correlates of sleep-disordered breathing in older men: Osteoporotic Fractures in Men Sleep Study. J Am Geriatr Soc 55(9):1356-1364

33. Redline S, Kump K, Tishler PV, Browner I, Ferrette V (1994) Gender differences in sleep disordered breathing in a communitybased sample. Am J Respir Crit Care Med 149(3 Pt 1):722-726

Publisher's note Springer Nature remains neutral with regard to jurisdictional claims in published maps and institutional affiliations. 